\title{
Avidyā e idolatria: diálogo necessário frente ao mal de nosso tempo
}

\author{
Avidyā and idolatry: necessary dialogue in the face \\ of the evil of our time
}

\section{Avidyā e idolatría: diálogo necesario ante el mal de nuestro tiempo}

\author{
Jung Mo Sung \\ Patricia Guernelli Palazzo Tsai
}

\begin{abstract}
RESUMO
O presente artigo visa trabalhar o diálogo entre dois conceitos de duas tradições religiosas distintas, mas que dividem um problema comum: o mundo em que vivemos de opressão, desigualdade e exclusão. De um lado será visto o conceito de avidyā da tradição budista, como trabalhado pelo XIV Dalai Lama, e de outro o conceito de idolatria usado pelo Papa Francisco, e como esses conceitos em diálogo servem de crítica à cultura de consumo e de exclusão. Palavras-chave: Avidyā; Dalai Lama; Papa Francisco; Idolatria.
\end{abstract}

\begin{abstract}
This article aims to work on the dialogue between two concepts from two different religious traditions, but which share a common problem: the world which we live in, one of oppression, inequality and exclusion. On one hand, the concept of avidya of the Buddhist tradition will be seen, as worked by the XIV Dalai Lama, and on the other, the concept of idolatry as used by Pope Francis, and how these concepts in dialogue serve to criticize the culture of consumption and exclusion.

Keywords: Avidyā; Dalai Lama; Pope Francis; Idolatry.

\section{RESUMEN}

Este artículo tiene como objetivo trabajar el diálogo entre dos conceptos de dos tradiciones religiosas diferentes, pero que comparten un problema común: el mundo en el que vivimos de opresión, desigualdad y exclusión. Por un lado, se verá el concepto de avidyā de la tradición budista, tal como lo trabajó el XIV Dalai Lama, y por otro, el concepto de idolatría usado por el Papa Francisco, y cómo estos conceptos en diálogo sirven para criticar la cultura del consumo y la exclusión.

Palabras clave: Avidyā; Dalai Lama; Papa Francisco; Idolatría.
\end{abstract}

\section{Introdução}

Há um consenso no mundo de hoje: a grande desigualdade social e a crise ambiental colocam em perigo a sustentabilidade social e ecológica da atual civilização. Em outras palavras, o mundo não pode continuar no caminho que estamos trilhando. Se não mudarmos, a humanidade entrará em 
colapso e teremos a morte de milhões e milhões de pessoas, talvez até de alguns bilhões, em um período não muito curto marcado pela fome, conflitos sociais e imigrações massivas que produzirão guerras e caos.

Diante de problemas tão fundamentais, pessoas de bom senso e de sensibilidade reconhecem que as diferenças políticas, culturais e religiosas devem ser colocadas em segundo lugar e devemos dialogar e agir para transformar o atual cenário e a tendência do futuro. No campo religioso, encontramos muitas lideranças, movimentos e grupos que estão engajados nesse diálogo e ação, porém sabemos também que esse processo de diálogo e cooperação não é fácil. Grupos que vem de tradições culturais e religiosas muito diferentes interpretam de forma diferente o problema comum, o que leva a mal entendidos não intencionais.

Nesse artigo, queremos contribuir com um estudo sobre a possível convergência entre a tradição budista e a bíblico-cristã na crítica à obsessão de consumo e posse do dinheiro no capitalismo de hoje. Para isso, vamos estudar o conceito de "avidyā" (ignorância distorciva), da tradição budista representada atualmente pelo Dalai Lama, e o conceito de "idolatria do dinheiro" no pensamento do Papa Francisco.

\section{Dois problemas globais e um consenso}

A grande maioria das pessoas marcada pelas dificuldades do dia a dia não debatem cotidianamente os temas da desigualdade social e a crise ambiental, mas eles estão no ar, na rede social e precisamos pensar seriamente sobre eles. O consenso é tão grande que até as instituições multilaterais responsáveis pela "administração" do capitalismo global, como o FMI e o Banco Mundial, assim como o famoso Fórum Econômico Mundial de Davos colocam a desigualdade social e a crise ambiental como os dois grandes desafios do capitalismo mundial.

Quando essas instituições - que estão no coração do atual sistema capitalista global, um sistema movido pela busca da acumulação ilimitada riqueza - estão preocupadas com o aumento da desigualdade social é porque a situação está insustentável. Para além do tema da crise ecológica, que é perfeitamente compreensível mesmo para os que não estão interessados nos problemas da pobreza, eles perceberam que a atual desigualdade social prejudica o funcionamento do capitalismo. Não é um problema de ética, para eles, mas de interesse próprio do capitalismo.

A partir dessa conclusão de que essas duas crises estão conectadas entre si, essas instituições e outros grupos começaram a defender uma reforma no 
interior do capitalismo: de um capitalismo tão excludente como o atual para um capitalismo "inclusivo". Em 2014, por exemplo, foi criada uma Coalizão para um Capitalismo Inclusivo (Coalition for Inclusive Capitalism) e, na sua primeira Conferência, a principal oradora foi a Christine Lagarde, na época a Diretora-Geral do Fundo Monetário Internacional. E nessa reunião estava presente um grupo de pessoas que juntas controlavam US $\$ 30$ trilhões em ativos financeiros (valor que atualmente seria em torno de $\mathrm{R} \$ 150$ trilhões; e para fins de comparação, o PIB brasileiro de 2019 foi de R \$ 7,3 trilhões, valor muito aquém do controlado pelo grupo mencionado).

Nesse objetivo por um capitalismo mais inclusivo, em última instância, eles não estão preocupados com o sofrimento e a morte dos pobres ou dos excluídos do mercado, mas sim a sustentabilidade da economia capitalista. Isto é, não defendem a inclusão e o direitos sociais de todos, mas sim a inclusão do número necessário para manter a lógica da acumulação do capital. É claro que, na perspectiva ética, é melhor um capitalismo mais inclusivo do que o atual neoliberalismo excludente que defende a insensibilidade social como uma "virtude" social, mas essa solução não é suficiente.

Por isso, há muitas outras pessoas e instituições que concordam com o tamanho da dupla crise, mas discordam com o diagnóstico da causa e a direção da reforma ou das transformações sociais necessárias. No campo religioso, encontramos diversas lideranças, igrejas e instituições que estão afirmando que essas duas crises têm, na verdade, uma única origem: o sistema capitalista que tem como o último objetivo a acumulação de riqueza, à custa da exploração dos trabalhadores, à exclusão dos pobres do mercado e da vida social, e da destruição da natureza (PAPA FRANCISCO, 2015). E essa estrutura econômico-social tem o seu lado subjetivo "espiritual": a obsessão da acumulação de riqueza e de consumo.

Essa lógica econômico-social capitalista que coloca em risco o futuro da humanidade é movido por o que Max Weber (2004) chamou de o "Espírito do Capitalismo", o espírito que coloca o ganhar o dinheiro acima de tudo, acima da felicidade ou prazer, e cria um novo deus, o Mammon, e uma nova espiritualidade, o consumo obsessivo. E essa obsessão de consumo, o materialismo, tem como contrapartida a insensibilidade social frente aos sofrimentos e mortes dos excluídos do mercado.

Diante de um grande desafio mundial como esse, que tem um caráter também espiritual, as grandes tradições religiosas devem assumir um papel fundamental, não apenas secundário. Pois, sem uma nova espiritualidade para o nosso tempo, que substitua o "espírito do capitalismo", não será possível superarmos essa dupla-crise. Afinal, com o processo da globalização, os 
problemas que nos ameaçam não são mais do Ocidente ou do Oriente, mas sim planetários. O que significa que a civilização Ocidental, com a hegemonia da cultura cristã, não será suficiente, assim como também a da civilização Oriental, com sua multiplicidade de culturas e religiões distintas.

Isto é, no pano de fundo da globalização econômico-capitalista, o desafio de diminuirmos o desejo obsessivo de consumo e do materialismo do mundo deve ser enfrentado em uma perspectiva multicultural e de pluralismo religioso. Isto é, em um diálogo onde muitos compartilham e assumem um problema comum e que reconhecem que nenhuma cultura ou religião pode dar conta sozinha. Afinal, diante de um problema tão complexo e global, precisamos de uma solução global. Só que a origem da causa é, ao mesmo tempo, (a) econômica, que é marcada pela racionalidade formal (cálculo econômico e tecnologia digital), e (b) cultural, o que significa multiplicidade de expressões e símbolos culturais (por exemplo, o desejo de consumo, que tem um caráter global, mas tem um reconhecimento social mediado por linguagem e valores culturais). No tema específico de um novo espírito para o mundo, é fundamental que lidemos com as diferenças linguísticas, culturais e religiosas. O que significa que precisamos aprender um longo caminho do diálogo cultural-espiritual.

Em resumo, frente à dupla-crise da desigualdade social e a crise ambiental, precisamos combater a cultura do consumismo que leva à insensibilidade social frente aos sofrimentos dos pobres e excluídos. Para isso, as grandes tradições religiosas precisam dialogar em torno desses problemas comuns, não em função das diferenças e semelhanças teológicas dogmáticas, mas para criarmos um espírito que seja capaz de desenvolver mais compaixão, solidariedade e justiça social e ambiental. Para isso, precisamos dialogar e aprender a dialogar - a ouvir e falar - com outros que têm culturas, conceitos e estruturas linguísticas diferentes para expressar sua fé e concepções ético-religiosas. Não é algo fácil, afinal cada grupo religioso compreende e expressa as suas experiências e crenças religiosas em uma linguagem e estrutura cultural que lhe parece "normal" e correta e interpreta a fala dos outros a partir da sua estrutura linguística religiosa. Mas, essa prática é necessária se queremos superar essa crise global.

Kwok Pui Lan, uma teóloga cristã chinesa, ao discutir sobre o problema do ensino e interpretação da bíblia em uma cultura não-bíblica, diz que "a tradição filosófica chinesa é muito diferente do pensamento ocidental, na medida em que não está interessada principalmente em questões metafísicas e epistemológicas. Pelo contrário, está mais preocupada com visões morais e éticas de uma boa sociedade" (KWOK, 2003, p. 11). 
A questão não é apenas da prioridade da metafísica ou da ética - que foi discutida também na tradição filosófica Ocidental - mas a própria diferença da lógica do pensar devido à diferença na estrutura da linguagem. No pensamento Ocidental, a proposição sujeito-predicado é o eixo principal da argumentação, ou de uma frase, e está relacionada ao verbo "ser" nos idiomas ocidentais. Esse verbo "ser" tem o significado da existência, uma substância - o que existe em si -, o que implica no "princípio da identidade". A noção de identidade tem a ver com o conjunto de características próprias e exclusivas com as quais se podem diferenciar pessoas, animas, plantas e objetos uns dos outros. Por outro lado, a lógica chinesa pode ser referida como 'lógica correlativa'. O pensamento chinês não enfatiza a exclusividade, mas enfatiza a qualidade relacional entre acima e abaixo, bem e mal, algo e nada" (KWOK, 2003, p. 34-35).

Além disso, as palavras chinesas escritas por meio de ideogramas têm sentido dentro do contexto, o que significa que não possuem inflexão e não há indicação de número, caso, pessoa, tempo verbal etc.

Não é objetivo deste artigo discutir a linguística ou a linguagem oriental, mas só queríamos mostrar um exemplo de como vivemos em um mundo de pluralismo cultural, ao mesmo tempo de globalização de única racionalidade econômico-social.

Retomando o nosso tema, que tem três aspectos, (a) da discussão da dupla-crise, (b) o desejo obsessivo de consumo e (c) a nova espiritualidade, queremos continuar a nossa reflexão tratando desse tema do desejo-espiritualidade em duas perspectivas culturais e religiosas convergentes: o tema da avidyā, "a ignorância distorciva", que vem da tradição budista e tem sido retomada pelo Dalai Lama, e o tema da idolatria do dinheiro, nos discursos do Papa Francisco, que tem a ver com o erro de tratar como Deus um ser que não é divino.

\section{Avidyā - Ignorância Distorciva}

Para a tradição budista, ${ }^{1}$ a avidyā, é a fonte de produção de sofrimentos mentais e emocionais nos seres humanos de maneira geral. Podemos dizer que é o elemento central do sofrimento. É a partir da avidyā que surgem

\footnotetext{
1 Quando falamos em tradição budista isso engloba uma diversidade de escolas e linhagens de diferentes países, sendo que todas de certa forma podem encontrar suas raízes ou na tradição Mabāyāna ou na Theravada. Uma generalização acerca dos pontos de ensinamentos do Buddha histórico para tentar fazer do Budismo uma categoria única é algo temerário, ainda mais porque houve desenvolvimento de características próprias de cada localidade, produzindo budismos e não um único.
} 
as outras duas aflições raízes ${ }^{2}: d v e s ̦ a$, ódio-ressentimento e upādāna, apego fixado. Mas como entender o que seriam esses termos?

Avidya é o termo em sânscrito que é mais comumente traduzido como ignorância, entretanto, há controvérsias acerca dessa tradução. Para Wayman (1957, p. 21), essa seria uma tradução incorreta do termo sânscrito por não captar inteiramente o que o termo transmite, uma vez que o termo avidya implica em algo mais sério e profundo do que ignorância do desconhecimento. O termo em sânscrito é composto por $a$, que é negação ou ausência de, e vidyā, que pode ser traduzido como conhecimento, filosofia ou ciência. Mas como diz Wayman, o conceito de avidyā não deve ser entendido simplesmente como "ignorância", mesmo que se amplie para o conceito de "ignorância espiritual" ou de "ilusão espiritual", em uma perspectiva europeia ou Ocidental.

Dentro da tradição sino-tibetana Geluk, da qual Tsongkhapa (séc. XIV) é fundador e da qual pertence o atual Dalai Lama, há discussão para explicar o que seria avidyā.

Em mandarim 無明 (wúming, tradicional), o conjunto dos caracteres tem sentido também de delusão. As traduções do termo em língua inglesa padronizaram o uso de avidyā como ignorância, entretanto, ao observar a profundidade do que o conceito realmente traz à tona, dificilmente o termo ignorância por si só daria conta. Não é uma ausência de conhecimento, mas sim um conhecimento que é uma visão distorcida ${ }^{3}$ da realidade.

O termo avidyā também pode ser traduzido como ignorância fundamental, como utilizado por Thupten Jinpa para a tradução de uma comunicação do Dalai Lama (1997, p. 57, 59 e 61).

Para corroborar a compreensão do termo, sem cair na incompletude do termo literalmente traduzido, temos também os dizeres do Dalai Lama (2014, p. 42): "é chamado de ignorância porque distorce a percepção da verdadeira natureza da realidade".

Para entendermos melhor a complexidade e a especificidade do conceito de avidya , nos ajuda a entender a diferença entre esse conceito e a noção de ajñaña que é discutidos no estudo dos textos budistas, Sütras:

\footnotetext{
${ }^{2}$ Dentro do cânone budista são encontradas as fontes para assim considerar como raízes as três aflições majoritárias: avidyā, upādāna e dveșa (em sânscrito), que geram todas as demais aflições mentais e emocionais. Muitas referências podem ser encontradas para corroborar com o trazido aqui, além das bibliografias e notas indicadas.

${ }^{3}$ Em mandarim avidyā é traduzido como 无明, wúmíng, na versão simplificada e na tradicional é 無明. De acordo com o Buddhist Dictionary of Chinese Terms, 無明 pode ser também traduzido como "não-iluminação" (p. 84). O primeiro ideograma 無 (wú) dá o sentido de vazio ou ausente de, e o segundo 明 (ming) traz a noção de brilho, visão e até mesmo justiça ou retidão.
} 
Para o Budismo, os termos em sânscrito "avidyā" e "ajñaña" são dois conceitos diferentes. Embora os contextos textuais de ambos termos sejam parcialmente coincidentes, na maioria dos casos, seus significados não são alternáveis. Avidyā é referida ao entendimento incorreto ou suposição distorcida, sobre a realidade. Assim, avidyà é o que a realidade não é. Ajñaña é referida na maior parte das vezes a falta de conhecimento sobre algo. É próximo ao entendimento geral de ignorância em inglês. Então, "ignorância" é usada para expressar ajñaña aqui. (WANG e WAWRYTKO, 2019, p. 237).

Por essas questões, a noção de ignorância por si só não traz a dimensão do que é avidyā. Por isso, há duas possibilidades de tradução: ignorância fundamental e ignorância distorciva.

Dentro da compreensão do termo de avidya, ou ignorância distorciva, ainda temos duas chaves para tentarmos dimensionar as distorções, que são a ideia de ahamkāra [senso de 'eu' inerentemente existente, sólido e imutável] e mamakāra [senso de 'meu' de maneira inerentemente existente, sólido e imutável], como trazido pelo Dalai Lama (2005, p. 53):

(...) nós nos agarramos primeiro a um sentido de eu, e então expandimos esse agarramento para os outros. Primeiro temos um senso de "eu", e então nos agarramos às coisas como "minhas". Por observarmos nossas próprias mentes, podemos perceber que quanto mais forte for o agarramento, mais forçosamente gera emoções negativas e destrutivas. Existe uma conexão causal íntima entre o nosso agarramento ao senso de eu e o surgimento de emoções destrutivas dentro de nós. Enquanto permanecermos no domínio dessa crença errônea, não teremos espaço para a alegria duradoura - isso é o que significa estar emprisionado no ciclo de existência. Sofrimento não é nada além do que existência escravizada pela ignorância distorciva.

Então, a ignorância distorciva assim é chamada porque ocorre um falseamento, uma percepção incorreta da realidade. Interpretamos a realidade e todos os nossos pensamentos, emoções e decisões acabam por ser condicionados ou contaminados por esse falseamento - a visão de um eu inerentemente existente, destacado e separado dos outros.

A noção de correto e incorreto se refere ao que produz sofrimentos e amplifica-os, como sendo incorretos, e a de correto seria o que reduz até extinguir esses sofrimentos. Essa maneira de utilizar os vocábulos correto/ incorreto é algo que também vem da estrutura da tradição budista, de maneira geral (comum às tradições Mahāyāna e Theravada).

Quando falamos de ignorância distorciva devemos antes diferenciar da ignorância comum, que é por falta de conhecimento, que seria outro termo segundo os Sütras (o termo ajñaña). A ignorância comum pode ser resolvida através da leitura, estudo e dedicação ao conhecimento, enquanto a ignorância distorciva não. 
A ignorância distorciva é a distorção da percepção da realidade que gera o egoísmo que leva para o individualismo. O egoísmo, como vimos acima, que enxerga a si mesmo como imutável, independente e substancial (existente em si e por si), surge com a ignorância distorciva, e se definindo assim como um ser independente dos demais, passa a agir e decidir com base na supremacia de seus próprios interesses, desconsiderando os demais a seu redor, e, ainda, desconsiderando a interdependência das relações - os seres em relação. Em outras palavras, a ignorância distorciva gera as percepções de um eu inerentemente existente, gerando o egoísmo e esse egoísmo leva ao individualismo.

A partir da ignorância distorciva, as visões errôneas e percepções equivocadas levam os indivíduos a agir incorretamente, com percepção enganosa sobre a realidade, e isso leva a consequências morais e éticas.

Pode parecer que há uma linearidade com relação ao surgimento e desenvolvimento da ignorância distorciva, entretanto, não é assim: ocorre de maneira interdependente. Mas a base fundamental para os sofrimentos e todas as consequências têm como ponto de partida a ignorância distorciva.

A ignorância distorciva, através da percepção equivocada de um eu eterno, imutável e independente de relações gera a upādāna, que é o apego fixado ou apego aflitivo, que implica em um agarramento aos objetos que dão prazer. Há que considerarmos que os indivíduos não escolhem viver sob domínio da ignorância distorciva, é algo que independe da vontade ou intenção - é a maneira pela qual aprendemos a construir a realidade que nos alcança e o filtro pelo qual observamos todas as demais coisas. Tsongkhapa sobre isso menciona (2012, p. 39):

Apego significa notar algo agradável ou atraente nos objetos internos ou externos e desejá-los. Quando apego gera o agarramento pelo objeto, e vai fortalecendo-o, é difícil de nos separarmos desse objeto, assim como é difícil de remover o óleo de uma roupa que foi embebida nele.

O apego fixado então é uma exacerbação das qualidades desejáveis do objeto, que leva a um desejo sedento, tṛṣnă, uma vontade de ter para si, mas de maneira em que não podemos ver outra saída a não ser ter o objeto em nossa posse, e que pode ser entendido também como cobiça. E com isso adentramos um ciclo vicioso de crença em ter, possuir objetos para ser único, diferenciado, satisfazendo os apetites. Esse apego fixado ou obsessivo a um objeto ou uma pessoa desejada leva a uma situação de ciclo vicioso que fica preso à essa cobiça, um tema também presente na tradição bíblico-cristã e aparece claramente no décimo do Dez Mandamentos.

Dveșa é o termo para ódio-ressentimento, que implica em aversão e repulsa aos objetos que provocam dor ou desprazer. Pode também ser 
traduzido como hostilidade. Como mencionado por Tsongkhapa, como um resumo dos três termos (2012, p. 32):

Portanto, o apego aumenta quando os sentimentos agradáveis surgem, e a hostilidade aumenta quando as dores surgem. Ignorância aumenta quando apreendemos erroneamente o corpo - que é parte de uma situação disfuncional que não é nem agradável nem dolorosa - como permanente, quando, na verdade, ele é impermanente.

O ódio-ressentimento ou hostilidade é também fruto da ignorância distorciva, e é uma distorção que exacerba as não-qualidades ou defeitos dos objetos. Entendemos então que o desprazer provocado pelo contato com esses objetos deve ser evitado a qualquer custo, podendo até mesmo fazer surgir o sentimento de exterminar o que nos provoca esse desprazer.

Por conta da visão distorcida da realidade, por acreditarmos cegamente em um 'eu' distinto e separado dos demais seres, acabamos por criar estruturas de relação entre o nosso 'eu' sólido e imutável e objetos de apego ou objetos de ódio-ressentimento.

E é nesse ponto, após sabermos sobre as três raízes aflitivas, tri-akuśalamüla, que podemos explicar o pensamento budista com relação ao desejo.

Nem todo desejo é necessariamente ruim, entretanto, o desejo que provoca uma fixação tal que acarreta uma busca incessante por conseguir aquele objeto é o que a tradição Mahāyāna chama de apego aflitivo, upādāna.

Quando esse desejo não é satisfeito, não sendo possível ter o objeto desejado, é que ocorre a frustração, que leva para o desprazer e rapidamente, na mesma intensidade em que foi estimulado e aumentado o apego fixado é que se dará o ódio-ressentimento.

Faz parte da compreensão distorcida da realidade o ideal de que felicidade é a satisfação de todos os nossos desejos emocionais, sensoriais, materiais, enfim, uma longa lista de tudo o que atribuímos com o potencial de providenciar felicidade duradoura.

Então as aflições da ignorância distorciva, apego fixado e ódio-ressentimento são centrais na compreensão do sofrimento. E por essa razão é que o primeiro sermão, ou Sütra, ensinado pelo Buddha histórico foi o Sütra das Quatro Verdades Superiores, mais conhecido por Dharma-cakra-vartana-sütra, e com isso há todo o desenvolvimento para perceber os sofrimentos e suas diferentes categorias, e como sair desse ciclo ${ }^{4}$.

\footnotetext{
4 De maneira bem resumida, as Quatro Verdades Superiores foram ensinadas dentro de uma estrutura lógica do contexto védico vivido pelo Buddha histórico, em que a Medicina era pensada dentro de quatro aspectos: diagnóstico, etiologia, prognóstico e receita, conforme TSAI (2017, p. 81). Pensando nesse problema, o Buddha expõe sua teoria com base na analogia entre sofrimentos e doenças. Então, as Quatro Verdades tratam da constatação de que existe sofrimento, duḥkha-ārya-satyā; de que os sofrimentos possuem causas para surgir, samudaya-ärya-satyā; de que é possível pôr um fim aos sofrimentos, nirodha-ärya-satyā, e; o caminho que leva para a cessação dos sofrimentos, märga-ärya-satyā.
} 


\section{Visão do XIV Dalai Lama sobre a avidyā}

A desumanização trazida pelo reforço do egó́smo e individualismo provocam danos estruturais intensos, tanto na economia, bem como nas demais esferas, tornando aceitável o desprezo pela noção de direitos humanos, e ainda mais justificável a exclusão dos que não servem (os não produtivos/ inúteis) ou não se adequam ao sistema.

É importante ressaltar que há interdependência também entre indivíduo e coletivo, sendo certo que a esfera individual resvala e se expande para a coletiva, e por essa razão, as três raízes dos sofrimentos passam a ser um problema global.

Por isso, não há uma solução simples para a questão, e a tradição budista coloca os efeitos que sentimos enquanto sociedade e coletividade como consequências das ações de cada um de seus membros e do coletivo.

A maneira para combater os efeitos aflitivos que geram todas essas consequências que vivemos no mundo de hoje é, como vem trabalhando publicamente o Dalai Lama, através da conscientização da responsabilidade universal.

As exigências, da coletividade e dos próprios indivíduos, aliados aos desejos infinitos de sucesso, prazer, felicidade enquanto produto passível de compra e posse, e ao mesmo tempo o isolamento social, a busca por soluções cada vez mais individualistas, reforçadas por todo um conjunto social, leva ao desequilíbrio tal que o indivíduo perde a noção de pertença a uma comunidade, gerando o isolamento, distanciamento e a insensibilidade em relação aos sofrimentos dos outros.

A longo prazo o pensar de maneira egoísta, individualista, leva para um exagero e falseamento da autoimportância, de tal maneira que os sofrimentos parecem ser muito mais insuportáveis do que o das demais pessoas.

Como afirma o Dalai Lama (2012, p. 141 e 142):

Cultivar contentamento é especialmente importante, penso eu, no mundo materialista de consumismo global, que vivemos hoje. A sociedade materialista coloca as pessoas em constante pressão para querer mais e gastar mais, mesmo quando suas necessidades básicas foram satisfeitas. Propagandas sofisticadas foram feitas para excitar a imaginação e gerar a percepção de que bens materiais nos farão felizes, e que enquanto não tivermos as últimas novidades de acessórios, dispositivos e itens de moda, isso não ocorrerá. O materialismo da sociedade moderna faz com que a prática da moderação e contentamento sejam uma necessidade diária se queremos resistir ao sucumbir aos sentimentos de insatisfação pessoal, nascido do desejo cobiçoso irrealista.

O alerta trazido pelo Dalai Lama não é algo exclusivo da tradição budista, entretanto, é um problema pouco discutido, especialmente no meio 
religioso, diante do fato de que é ir na contramão das tendências globais e mercadológicas, que enaltecem características de imediatismo e desejo desenfreados, de "ter para ser".

A adoção do egoísmo e da individualidade extremada como ponto de partida do entendimento da realidade traz graves consequências não apenas em âmbito religioso, mas envolve também camadas multifacetadas da dinâmica social. Elas produzem como efeito colateral a desumanização do ser humano em todas as esferas, bem como uma valorização excessiva de um modo de pensar e viver doentio, ocorrendo gradativamente um reforço no estímulo da avidyā e da afeição aflitivo, inflando também a dve $\square$ a e upädāna, tornando seres humanos em indivíduos isolados e compartimentados, narcisistas e repletos de transtornos. E, quando não é mais possível conviver nesse modus operandi, há uma enorme sensação de 'vazio' que não pode ser preenchido permanentemente, uma vez que o consumo desenfreado, a competição por ter e ser já não mais conseguem dar conta de conferir um sentido à vida humana.

Sobre a competição o Dalai Lama faz uma analogia entre a sociedade moderna, amplamente focada no progresso como uma máquina alheia ao sofrimento humano e do mundo, pois não é impulsionada pelos seres humanos, mas estes são componentes insignificantes obrigados a mover quando a máquina se move, e "o que gera essa situação é a retórica contemporânea de crescimento e desenvolvimento econômico, que reforça intensamente a tendência das pessoas para a competitividade e a inveja" (2000, p. 18).

E mais, tanto na esfera individual quanto na coletiva o problema surge pela insatisfação, que é impulsionada pela cobiça e ganância, e que por sua vez plantam a semente da inveja e competitividade agressiva que leva a uma cultura de excessivo materialismo (DALAI LAMA, 2000, p. 181). Isso tudo leva a problemas estruturais sociais, a uma desigualdade gritante, tudo por conta de um desejo de progresso e acumulação infinitos, que não podem ser satisfeitos ou realizados.

\section{Papa Francisco e a idolatria}

Esse último parágrafo, que sintetiza o pensamento do Dalai Lama na seção anterior, não é um problema dos budistas ou do budismo, mas é dos seres humanos em geral, especialmente na cultura capitalista global do nosso tempo. Não é à toa que muitas das lideranças do cristianismo têm falado na mesma direção. Como por exemplo o Papa Francisco e as lideranças do Conselho Mundial das Igrejas. Isso não quer dizer que não exista diferenças entre o budismo e o cristianismo em termos de doutrina e conceitos teo- 
lógicos. Mas, diante aos grandes desafios comuns do mundo, é possível e é necessário dialogar com outras lideranças e movimentos culturais e religiosos, reconhecendo as diferenças específicas de cada grupo.

O Papa Francisco (2015), no seu documento Laudato Si ("Louvado Sejas"), em convergência com o pensamento do Dalai Lama, diz que "os poderes econômicos continuam a justificar o sistema mundial atual [...] que tendem a ignorar todo o contexto e os efeitos sobre a dignidade humana e sobre o meio ambiente" (n. 56) e que "o mercado tende a criar um mecanismo consumista compulsivo para vender os seus produtos" e "as pessoas acabam por ser arrastadas pelo turbilhão das compras e gastos supérfluos. O consumismo obsessivo é o reflexo subjetivo do paradigma tecno-econômico" (n. 203).

Equivoca-se quem pensa que o Papa está tratando de um tema meramente econômico e que estaria lidando com um problema não religioso ou teológico. Ao contrário, ele usa um conceito teológico, a "idolatria", "idolatria do dinheiro" e o "mercado divinizado", para criticar em uma perspectiva teológica o sistema capitalista atual. Essa é uma diferença entre o discurso dele e o de Dalai Lama. O Papa Francisco usa esse conceito de idolatria, que vem da tradição bíblica e diferencia o Deus verdadeiro de um deus-falso, que é adorado por seus idólatras como um ser divino. Mais do que isso, ele não reduz o tema da idolatria ao problema do "erro de representação", isto é, o erro de tomar a imagem como se fosse a realidade de Deus ou dos seres divinos que pretende a representar (HALMBERT; MARGALIT, 1992). O que seria um problema meramente religioso ou teológico, sem nenhuma relação com os temas econômico-social, a desigualdade social, e o da crise ambiental. Mas, ele associa a noção de idolatria com a de dinheiro e o consumo obsessivo (SUNG, 2018).

O que nós queremos chamar atenção é que o Papa não reduz o problema da idolatria ao de confundir uma imagem sagrada - seja uma estátua, uma palavra ou um ritual sagrado - com a realidade transcendente de Deus, como o fazem muitos teólogos e filósofos. Ele usa a noção de idolatria ao campo econômico-social porque ele detecta nessa área o erro de transformar um sistema econômico em um sistema de "mercado absolutizado", um erro que se desdobra no processo subjetivo de adorar o dinheiro e viver sob o desejo obsessivo de consumo. É nesse sentido que o Papa Francisco se aproxima mais com Dalai Lama do que com os teólogos que tratam do tema da idolatria, mas não articulam esse tema com os desafios econômicos e ambientais.

No documento Evangelii Gaudium ("Alegria do Evangelho"), o Papa Francisco (2013) chama atenção à "nova idolatria do dinheiro" que domina no mundo e diz que "A crise financeira que atravessamos faz-nos esquecer 
que, na sua origem, há uma crise antropológica profunda: a negação da primazia do ser humano. Criamos novos ídolos" (n. 55). É importante destacar a relação entre a idolatria e a crise antropológica. Normalmente as pessoas que discutem o erro da idolatria e a criação de novos ídolos tratam do erro teológico, ou da crise da fé em Deus. Entretanto, o Papa associa a idolatria a um problema antropológico. Logo a seguir à afirmação de que criamos novos ídolos, ele diz: "A adoração do antigo bezerro de ouro (cf. Ex 32, 1-35) encontrou uma nova e cruel versão no fetichismo do dinheiro e na ditadura duma economia sem rosto e sem um objetivo verdadeira mente humano".

Se esse problema da idolatria do dinheiro fosse entendido como uma crise teológico-religiosa, a solução ou o caminho da solução passaria necessariamente por uma concepção teológico-religiosa sobre o Deus e isso nos levaria a uma discussão teológica que estão marcadas profundamente por diferenças culturais e linguísticas. Não somente as diferenças culturais, linguísticas e de escolas teológicas entre os católicos, protestantes e pentecostais no âmbito cristão, mas também às diferenças entre os cristãos, judeus, islâmicos, budistas e outros e perderíamos a visão do problema real: os sofrimentos dos seres humanos e a crise ambiental que vai afetar a todos.

Sabemos que o necessário diálogo pressupõe termos um problema comum que nos une e sabemos também que os participantes do diálogo só podem dialogar na medida em que expressam suas ideias e entendem a fala dos outros a partir da sua cultura e das suas concepções religiosas (FREIRE, 1977). E o Papa apresenta esses dois aspectos: a) o problema em discussão é de caráter antropológico, humano, - que afeta todos os seres humanos independentemente da sua cultura, classe social, raça e gênero, religioso ou não - e, portanto, pode e deve ser discutido por todos que estão preocupados com a desigualdade social e a crise ambiental; b) como cristão, o Papa apresenta o seu diagnóstico e caminhos de solução por e no interior da tradição bíblico-cristã.

É preciso deixar claro que para o Papa Francisco a centralidade da crise antropológica não se opõe à crise da fé no mundo moderno. Pois para ele não há separação entre a crise antropológica e a teológica: "Por detrás desta atitude, escondem-se a rejeição da ética e a recusa de Deus" (2013, n. 57). E a recusa do Deus da Vida tem relação com a idolatria do dinheiro e do mercado absolutizado. Essa idolatria coloca o dinheiro e as leis do mercado acima da vida dos não-consumidores, dos pobres.

Desde a origem da tradição bíblica, desde a manifestação de Javé ao Moisés, Deus de Israel e de Jesus sempre aprece na história das comunidades como uma força que está além das religiões e dos impérios, incontrolável, no 
seu desejo de anunciar a liberdade contra todas as formas de escravidão. É essa fé em Deus que o Papa Francisco retoma para reafirmar a articulação entre o antropológico e o teológico: “Deus é incontrolável, não manipulável e até mesmo perigoso, na medida em que chama o ser humano à sua plena realização e à independência de qualquer tipo de escravidão" (n. 57).

\section{Diálogo que nos leva à verdade que liberta}

Como colocamos no início do artigo, o nosso objetivo não é um diálogo inter-religioso ou intercultural para estabelecermos um entre o budismo e o cristianismo, ou entre o pensamento do Dalai Lama e do Papa Francisco, sobre semelhanças e diferenças de alguns conceitos teológicos ou religiosos. Partimos do pressuposto de que algumas diferenças linguísticas e culturais entre essas duas tradições religiosas e culturais são insuperáveis e, o mais importante, que essas discussões não são prioritárias frente aos grandes e urgentes problemas da humanidade. Por mais que dialoguemos em questões teológico-metafísicas não chegaremos a um tipo de "religião universal" capaz de unificar os pressupostos que os separam.

Por outro lado, a partir da mesma sensibilidade ética ou do mesmo tipo de compaixão frente aos sofrimentos das pessoas e do mesmo reconhecimento da crise econômico-social-ambiental que vivemos, podemos perceber os mesmos problemas e os mesmos tipos de "ignorância distorciva" ou do erro de uma idolatria do dinheiro. A crítica da cultura desumanizadora que despreza os direitos humanos, que gera a insatisfação sem fim impulsionada pela cobiça e ganância, a inveja e competitividade agressiva que levam ao excesso do materialismo, e a justificação desse consumismo obsessivo em nome do "mercado divino" ou "absoluto" está presente tanto no budismo do Dalai Lama como no cristianismo do Papa Francisco.

No pensamento do Dalai Lama, o conceito de "ignorância distorciva", avidyā, tem um papel fundamental, enquanto no do Papa é o de "idolatria do dinheiro". O mais importante não é essa diferença entre as duas estruturas religiosas e linguísticas dos seus discursos, mas sim a convergência sobre o mesmo problema e os mesmos caminhos. No fundo, os dois compartilham a mesma perspectiva e o mesmo desejo de chegarmos à verdade que nos humaniza e nos liberta das situações e relações interpessoais e sociais que nos oprimem.

Esse tipo de diálogo inter-religioso e análise no campo do estudo das religiões é útil, urgente e fundamental para criarmos juntos uma cultura mais espiritual, humanizadora e defensora da vida de todas as pessoas e do meio ambiente. 


\section{Referências bibliográficas}

DALAI LAMA, Tenzin Gyatso. Beyond religion. New York: Mariner Books, 2012.

DALAI LAMA, Tenzin Gyatso. Essence of the heart sutra. Sommerville: Wisdom, 2005.

DALAI LAMA, Tenzin Gyatso. Four noble truths. London: Thorsons, 1997.

DALAI LAMA, Tenzin Gyatso. The middle way. Sommerville: Wisdom, 2014.

DALAI LAMA, Tenzin Gyatso. Uma ética para o novo milênio. Rio de Janeiro: Sextante, 2000.

FREIRE, Paulo. Pedagogia do oprimido. Rio de Janeiro: Paz e Terra, 1979.

HALBERTAL, Moshe; MARGALIT, Avishai. Idolatry. Cambridge; London: Harvard University Press, 1992.

KWOK, Pui Lan. Discovering the Bible in the non-biblical world. Eugene: Wipf and Stock, 2003.

PAPA FRANCISCO. Evangelii Gaudium. Roma: Libreria Editrice Vaticana, 2013.

PAPA FRANCISCO. Laudato Si. Roma: Libreria Editrice Vaticana, 2015.

SUNG, Jung Mo. A idolatria do dinheiro e os direitos humanos: uma crítica teológica do novo mito do capitalismo. São Paulo: Paulus, 2018.

TSAI, Plínio Marcos. História da tradição budista indiana. Valinhos: ATG, 2017.

TSONGKHAPA, Lobsang Dragpa. Lamrim Chenmo. Tomo II. Trad. Plínio Marcos Tsai, Valinhos: ATG, 2012.

VARELA, Francisco; THOMPSON, Evan; ROSCH, Eleanor. The embodied mind cognitive science and buman experience. Cambridge: MIT Press, 2017.

WANG, Youru; WAWRYTKO, Sandra A. Dao companion to chinese buddhist philosophy. Dordrecht: Springer, 2019.

WAYMAN, Alex. The meaning of unwisdom (Avidya). Philosophy East and West, Honolulu, v. 7, n. 1-2, p. 21-25, 1957. [Acessado em 28 de março de 2020. DOI:10.2307/1396830].

WEBER, Max. A ética protestante e o espírito do capitalismo. São Paulo: Companhia das Letras, 2004.

Submissão: 09-09-2020

Aceito: 21-11-2020 